\title{
Cancer cachexia differentially regulates visceral adipose tissue turnover
}

\author{
Felipe de Oliveira Franco', Magno Alves Lopes', Felipe dos Santos Henriques', \\ Rodrigo Xavier das Neves², Cesário Bianchi Filho³ and Miguel Luiz Batista Jr1,2 \\ 'Laboratory of Adipose Tissue Biology, Center for Integrated Biotechnology, University of Mogi das Cruzes, \\ Mogi das Cruzes, Brazil \\ ${ }^{2}$ Cancer Metabolism Research Group, Institute of Biomedical Sciences, University of São Paulo, São Paulo, Brazil \\ ${ }^{3}$ Center for Clinical and Translational Research, University of Mogi das Cruzes, Mogi das Cruzes, Brazil
}

Correspondence should be addressed to M L Batista Jr Email miguelj@umc.br

\begin{abstract}
Cancer cachexia (CC) is a progressive metabolic syndrome that is marked by severe body weight loss. Metabolic disarrangement of fat tissues is a very early event in CC, followed by adipose tissue (AT) atrophy and remodelling. However, there is little information regarding the possible involvement of cellular turnover in this process. Thus, in this study, we evaluated the effect of CC on AT turnover and fibrosis of mesenteric (MEAT) and retroperitoneal (RPAT) adipose tissue depots as possible factors that contribute to AT atrophy. CC was induced by a subcutaneous injection of Walker tumour cells $\left(2 \times 10^{7}\right)$ in Wistar rats, and control animals received only saline. The experimental rats were randomly divided into four experimental groups: 0 days, 4 days, 7 days and 14 days after injection. AT turnover was analysed according to the Pref1/Adiponectin ratio of gene expression from the stromal vascular fraction and pro-apoptotic CASPASE3 and CASPASE9 from MEAT and RPAT. Fibrosis was verified according to the total collagen levels and expression of extracellular matrix genes. AT turnover was verified by measurements of lipolytic protein expression. We found that the Pref1/Adiponectin ratio was decreased in RPAT $(81.85 \%, P<0.05)$ with no changes in MEAT compared with the respective controls. CASPASE3 and CASPASE9 were activated on day 14 only in RPAT. Collagen was increased on day 7 in RPAT (127\%) and MEAT (4.3-fold). The Collagen1A1, Collagen3A1, Mmp2 and Mmp9 mRNA levels were upregulated only in MEAT in CC. Lipid turnover was verified in RPAT and was not modified in CC. We concluded that the results suggest that CC affects RPAT cellular turnover, which may be determinant for RPAT atrophy.
\end{abstract}
Key Words
- cancer cachexia
- adipose tissue
- cellular turnover
- extracellular matrix
- apoptosis

Journal of Endocrinology (2017) 232, 493-500

\section{Introduction}

Cancer cachexia (CC) is a progressive multifactorial syndrome that affects approximately $60-80 \%$ of all patients with advanced cancer and is directly associated with $22-40 \%$ of all cancer deaths (Blum et al. 2014). Body weight loss is the main marker of cachectic syndrome, followed by atrophy of both skeletal muscle and adipose tissue (AT) (Das et al. 2011, Batista et al. 2012,
Seelaender \& Batista 2014). In this regard, several studies have postulated that AT atrophy is caused by (1) increased lipolysis in adipocytes (Agustsson et al. 2007, Ryden et al. 2008, Arner \& Langin 2014); (2) reduction of lipogenesis (Ebadi \& Mazurak 2014); (3) downregulation of adipogenic and lipogenic gene expression (Bing et al. 2006, Batista et al. 2012) and (4) disruption of the 
formation and development of AT (Arner \& Spalding 2010). However, few studies have addressed AT turnover in CC.

Recently, some murine models of cancer cachexia have shown a heterogeneous response from different AT depots, considering its remodelling process induced by cachexia syndrome (Bing et al. 2006, Batista et al. 2012, Petruzzelli et al. 2014). In particular, such studies have focused on inflammation, rearrangements of the extracellular matrix (ECM) and metabolic chaos, which seem to occur differently in AT depots (i.e., visceral and subcutaneous) (Bertevello \& Seelaender 2001, Machado et al. 2004, Bing et al. 2006, Batista et al. 2012, 2013, 2016, Beluzi et al. 2015). In our previous study, cachectic animals (Walker-256-induced) showed more accentuated atrophy in the retroperitoneal adipose tissue (RPAT) compared with another visceral depot, such as mesenteric adipose tissue (MEAT) (Batista et al. 2012).

In $\mathrm{AT}$, cellular turnover is regulated by a balance between the growth/differentiation (adipogenesis) and death of its cells (generally by apoptosis) (Warne 2003, Arner \& Spalding 2010). Some studies have elucidated the adipogenic marker profile during development of cachexia syndrome (Bing et al. 2006, Batista et al. 2012); however, few studies have addressed the apoptotic processes and/or AT turnover during cachexia (Ryden et al. 2008). It has been known that adipogenic genes are downregulated in CC from epididymal AT (Bing et al. 2006) and RPAT (Batista et al. 2012). On the other hand, subcutaneous AT apoptosis did not change in cancer patients (Ryden et al. 2008). Thus, considering that AT depots respond heterogeneously to $\mathrm{CC}$ and several metabolic and inflammatory pathways are involved in AT remodelling, additional studies are needed to achieve a deeper understanding of the possible role of AT turnover in cachexia.

The ECM plays a key role in angiogenesis (Lafontan 2014) and modulates adipogenesis, cell death and inflammation (Mariman \& Wang 2010). Among the components of the ECM, type 1 collagen has unique importance in structuring of mesenchymal tissue (Sun et al. 2013). The level of extracellular matrix components depends on a fine balance between synthesis and degradation. Collagen degradation is controlled by matrix metalloproteinases (MMPs), which are modulated by tissue inhibitors of metalloproteinases (TIMPs) (Su et al. 2016). Finally, the primary modulator for balance between MMPs and TIMPs appears to be TGFB (Su et al. 2016), an important cytokine that regulates fibrosis (Allison 2014, Craft 2015) and inflammation (Sanjabi et al. 2009, Craft 2015). The balance of these
ECM components is important for the regulation of collagen deposition, and this balance maintains normal tissue function (Iwayama et al. 2015). In obesity, ECM from AT is subjected to a remodelling process that occurs as a change in size and/or number of adipocytes (Craft 2015). On the other hand, in CC, increased fibrosis in AT in response to syndrome development has recently been demonstrated in a murine model (Bing et al. 2006) and in humans (Batista et al. 2016), which contributes to AT rearrangement (Batista et al. 2016).

Therefore, to study AT turnover during the development of CC, we analysed the visceral depots in two stages of cachexia (early and cachexia stages) after tumour induction. The analysis showed the downregulation of adipogenic markers as well as apoptotic markers, indicating a possible change in RPAT cellular turnover. This condition becomes even more evident in the last stages of the disease. Furthermore, the results suggested that RPAT atrophy induced by CC appears to be largely due to failure of cellular turnover than other metabolic mechanisms or remodelling of AT.

\section{Materials and methods}

\section{Animals and adipose tissue collection}

Male adult Wistar rats (200-280g), obtained from the University of Mogi das Cruzes Animal Facility, were maintained in plastic cages in a 12-h light:12-h darkness cycle (lights on at 07:00h) under controlled temperature conditions $\left(22 \pm 1^{\circ} \mathrm{C}\right)$ and received water and food (NuvilabCR1-Nuvital S/A, Colombo, PR, Brazil) ad libitum. The Ethical Committee for Animal Research from the University of Mogi das Cruzes approved all of the adopted procedures, which were carried out in accordance with the ethical principles stated by the Brazilian College of Animal Experimentation (Filipecki et al. 2011).

To induce CC, Walker 256 tumour cells $\left(2 \times 10^{7}\right.$ cells) were injected s.c. into the right flank of animals (Bertevello \& Seelaender 2001). Walker 256 cells were obtained from the American Type Culture Collection (ATCC) constituting our repository of cancer cell lines. The cell preparation protocol included: (1) initial cells submitted to sub-culture (in vitro phase); (2) intraperitoneal cells injection ranging 5-7 days (doubling time, in vivo phase); and (3) isolation of viable cells, considering cells morphology and growth rate. Control rats received saline injections on the same day of tumour inoculation. Animals were held in a collective

Published by Bioscientifica Ltd. 
Table 1 General characteristics of animal groups during the progression of cancer cachexia.

\begin{tabular}{|c|c|c|c|c|}
\hline & \multicolumn{4}{|c|}{ Tumour cells inoculation (days) } \\
\hline & \multicolumn{2}{|c|}{7} & \multicolumn{2}{|c|}{14} \\
\hline & Control & TB & Control & TB \\
\hline$n$ & 5 & 8 & 6 & 8 \\
\hline $\mathrm{BW}(\mathrm{g})$ & $264 \pm 14$ & $247 \pm 11$ & $285 \pm 13$ & $255 \pm 12^{*}$ \\
\hline BW loss (\%) & - & 6.3 & & 10.7 \\
\hline$\triangle B W(g)$ & $19.7 \pm 2.1$ & $6.5 \pm 1.1 *$ & $29.3 \pm 3.0$ & $15.5 \pm 1.5 *$ \\
\hline TM (g) & - & $4.4 \pm 1.8$ & - & $12.1 \pm 3.1$ \\
\hline TM (\%) & - & $1.8 \pm 0.5$ & - & $4.7 \pm 1.0$ \\
\hline FI (g/day) & $22.1 \pm 0.3$ & $21.7 \pm 0.4$ & $24.1 \pm 0.7$ & $22.0 \pm 0.5$ \\
\hline
\end{tabular}

Values are mean \pm S.E.M. for five to eight animals per group. $\star P<0.05$ relative to the control group.

BW, body weight; Fl, food intake; TB, tumour-bearing; TM, tumour mass; $\Delta$, delta of body weight of the animals from days 7 to 14 in relation to day 0 .

cage, containing five animals/cage. Weight was assessed daily and food intake was assessed on days 7 and 14 after injection, always in the afternoon. Cachectic syndrome was observed in rats bearing Walker 256 tumour cells after 10-15 days (Machado et al. 2004). To evaluate the development of CC, experiments were carried out in the time course study when rats were killed by decapitation (12 h fasting) on days $0,4,7$ or 14 after injection (five to eight animals for each time point). Animals without tumour inoculation and with only vehicle solution were used as controls. Because of the absence of food intake (Table 1), all experimental results were compared with the control group. Mesenteric adipose tissue (MEAT, after careful removal of adjacent lymph nodes), retroperitoneal adipose tissue (RPAT) and tumours were removed, weighed, snap-frozen in liquid nitrogen and stored at $-80^{\circ} \mathrm{C}$.

\section{PicroSirius red staining}

MEAT and RPAT were fixed by HistoChoice MB (Amresco, Solon, OH, USA) at pH 7.4 for $2 \mathrm{~h}$. Samples were processed as described by Junqueira and Brentani (Junquiera et al. 1979) with minor modifications. Five micrometre sections were obtained with a Leica microtome (Aotec Scientific Instruments LTDA, São Paulo, SP, Brazil).

\section{Light microscopy and software analysis}

The slides were visualised via microscopy using a Leica DM 750 (Aotec Scientific Instruments) and captured with a Leica DFC 295 camera (Aotec Scientific Instruments) and LAS software (Aotec Scientific Instruments). After image capture, images were analysed with ImageJ software (http://rsb.info.nih.gov/ij/). The numbers of positive collagen staining per area were counted under 400 magnification, in at least 3 independent sections, with at least 10 fields per section for each adipose tissue sample, by 2 independent investigators who did not know the origin of the samples.

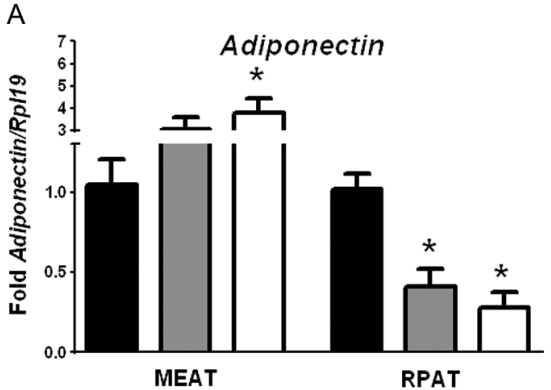

C

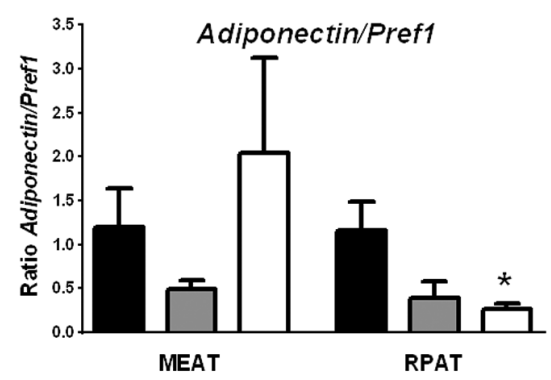

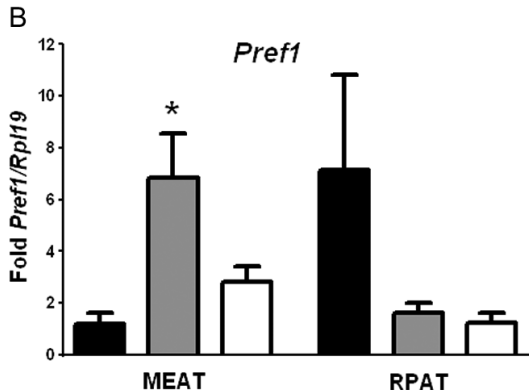

$\mathrm{D}$

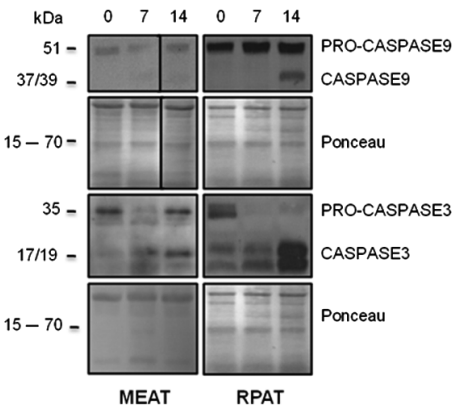

Figure 1

Adipogenesis markers and CASPASE cleavage during cancer cachexia. qPCR of mRNA gene expression of Adiponectin (A) and Pref1 (B) from the stromal vascular fraction of MEAT and RPAT. qPCR was normalized to Rp/19 (housekeeping gene). Values are the mean \pm S.E.M. for five animals per group. * Ratio between Pref1 and adiponectin expression; Pref1/Adiponectin ratio (C); (D) Western blot analysis of CASPASE3 and CASPASE9 relative to Ponceau red staining; days after tumour cells injection (or saline - control): 0 (control), 7 and 14 . $* P<0.05$ relative to the control group. MEAT, mesenteric adipose tissue; RPAT, retroperitoneal adipose tissue. http://joe.endocrinology-journals.org
DOI: 10.1530/JOE-16-0305

(c) 2017 Society for Endocrinology Printed in Great Britain 


\section{Stromal vascular fraction (SVF) cells and adipocyte isolation}

SVF cells and adipocyte isolation were adapted from Neves and coworkers (Neves et al. 2015), as well as Rodbell's method (Rodbell 1964) with minor modifications.

\section{Gene expression}

Real-time PCR was performed as described by Batista and coworkers (Batista et al. 2012). The gene sequences are shown in Supplementary Table 1 (see section on supplementary data given at the end of this article). All the primer sequences were obtained from Invitrogen (Life Technologies). Samples were normalised to the $18 \mathrm{~S}$ and Rpl19 values, and the results are expressed as fold changes of the $C_{\mathrm{t}}$ values relative to those of controls using the $2^{-\Delta \Delta C t}$ formula.

\section{Western blot}

Western blot analyses were performed as described in Batista and coworkers (Batista et al. 2012). The primary antibodies were against CASPASE3 (1:1000 dilution), CASPASE9 (1:1000 dilution), HSL LIPE (1:4000 dilution) and HSLphos563, 565 and 660 (1:1000 dilution). All primary incubations were conducted overnight, and secondary anti-rabbit IgG antibodies were conjugated to HRP (1:3000 dilution); anti-mouse IgG was conjugated to HRP (1:3000 dilution) for $1 \mathrm{~h}$ at room temperature. All antibodies were obtained from Cell Signalling Technology (Cat. number 9662S, 9508S, 4139, 4137, 4126, 7074 and 7076) or Abcam (Cat. number ab45422).

\section{Statistical analysis}

Data were analysed with one-way or two-way ANOVA followed by Bonferroni's post hoc comparisons tests using GraphPad Prism software for Macintosh, version 5.0 (GraphPad). $\quad P<0.05$ was considered significant for all statistical tests. Data are expressed as the mean value \pm S.E.M.

\section{Results}

The progression of CC was assessed on days 7 (early stage) and 14 (cachectic stage). Walker tumour cells induced CC as expected, in particular considering AT atrophy and tumour mass growth (Machado et al. 2004,
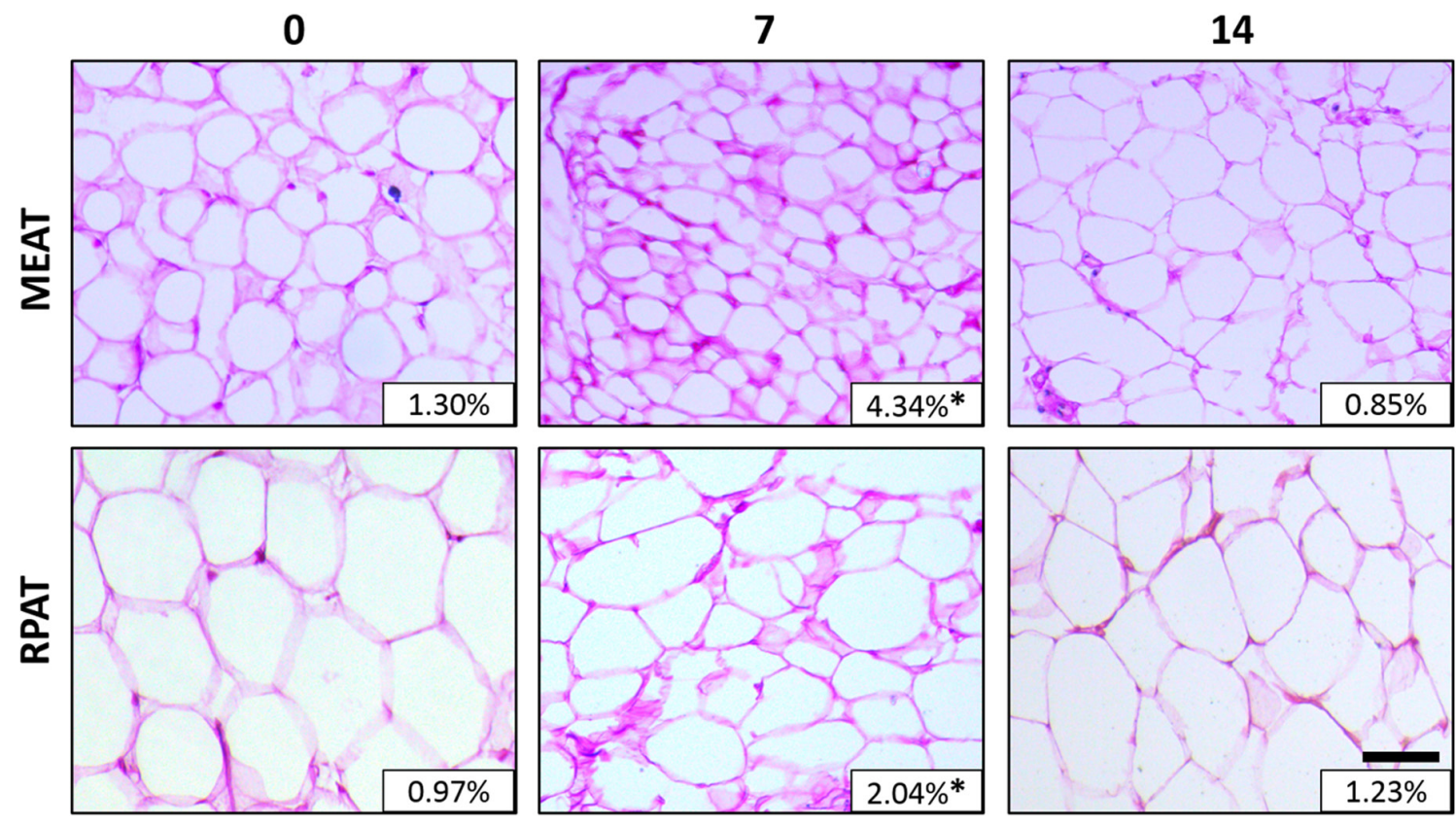

Figure 2

Adipose tissue total COLLAGEN content during cancer cachexia. PicroSirius staining (total COLLAGEN marker) micrographs of MEAT and RPAT during cachexia development; days after tumour cells injection (or saline control): 0 (control), 7 and 14 . The quantification of the total COLLAGEN content is shown at the bottom of each micrograph, and the values are expressed as the percentage of the total area. ${ }^{*} P<0.05$ relative to the control group. MEAT, mesenteric adipose tissue; RPAT, retroperitoneal adipose tissue; Scale bar, $100 \mu \mathrm{m}$. A full colour version of this figure is available at http://dx.doi. org/JOE-16-0305 

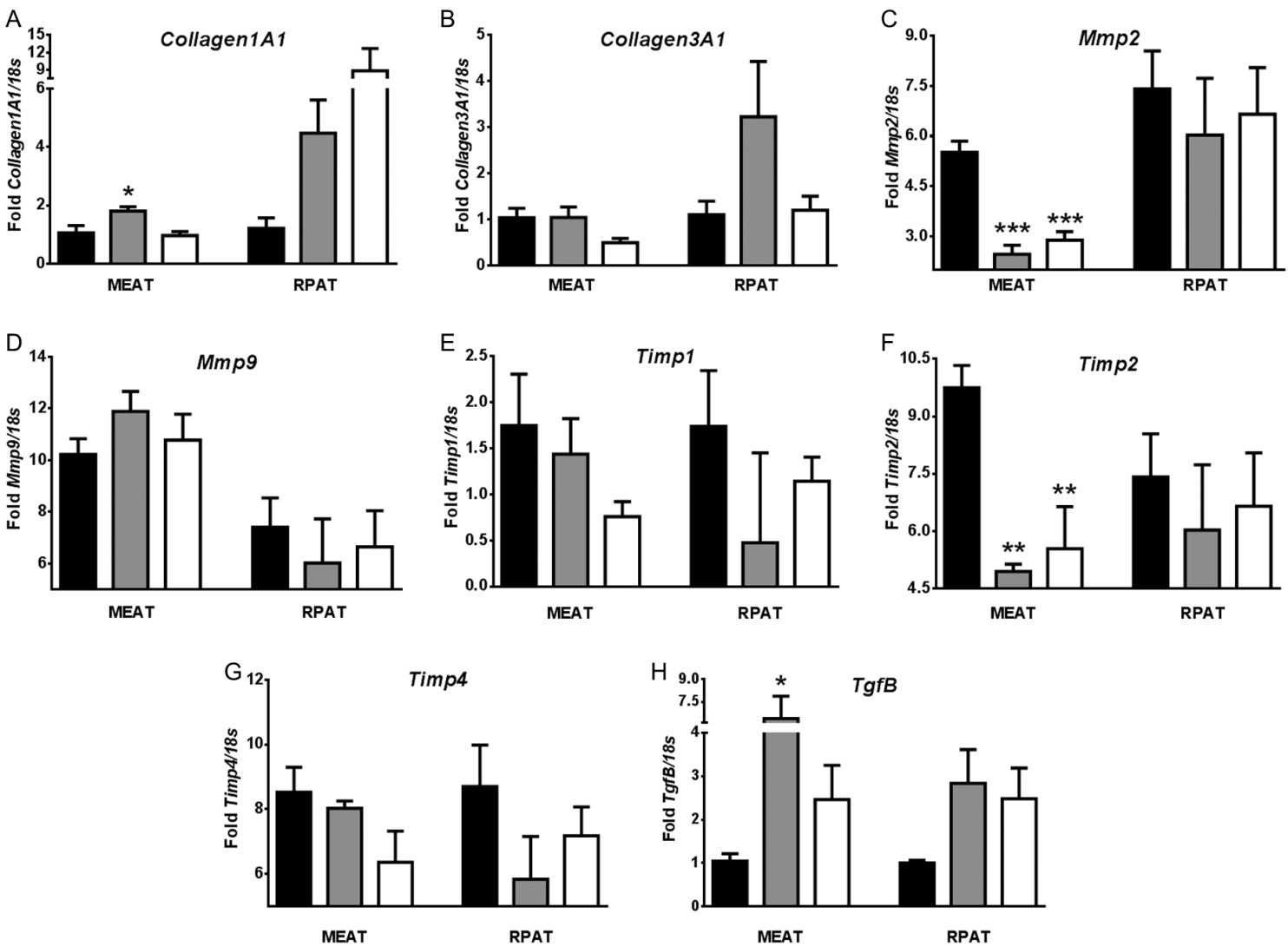

Figure 3

qPCR of extracellular matrix components during cachexia development. Collagen1A1 (A), Collagen3A1 (B), Mmp2 (C), Mmp9 (D), Timp1 (E), Timp2 (F), Timp4 (G), TgfB (H). The targets were normalized to $18 \mathrm{~s}$ (A and B) and Rp/19 (C, D, E, F, G and H) housekeeping genes. Values are the mean \pm S.E.M. for five animals per group. ${ }^{*} P<0.05$ and $* * P<0.01$ vs day 0 (control group). MEAT, mesenteric adipose tissue; RPAT, retroperitoneal adipose tissue.

Batista et al. 2012, Beluzi et al. 2015). Body weight loss was evident on day 14 , showing a reduction of $10.7 \%$, when compared with the same day control. Food intake for the four groups over the 14 days of treatment was similar (Table 1). To evaluate cell turnover, we measured the mRNA levels of Pref1 (pre-adipocyte marker) because its expression is linked to adipogenesis inhibition ( $\mathrm{O}^{\prime}$ Connell et al. 2011) and the mRNA levels of Adiponectin, which have been used as a marker of mature adipocytes found in the SVF (Martella et al. 2014). There was no change in Pref1 expression in the SVF from RPAT samples at days 7 and 14 (Fig. 1B). However, Pref1 expression increased 4.5-fold $(P<0.05)$ only on day 7 in the SVF MEAT (Fig. 1B). Gene expression of the Adiponectin from the SVF decreased $61.6 \%(P<0.05)$ on day 7 and $78.6 \%(P<0.05)$ on day 14 (Fig. 1A) in RPAT. On the other hand, Adiponectin increased 2.2-fold $(P<0.05)$ in the SVF from MEAT only on day 14 (Fig. 1A). Although the ratio of Adiponectin and Pref1 gene expression in the SVF cells from RPAT decreased $81.8 \%$ $(P<0.05)$ on day 14 , no change was detected in MEAT (Fig. 1C). Considering the apoptotic parameters, cleavage

\begin{tabular}{|lr}
\hline http://joe.endocrinology-journals.org & (c) 2017 Society for Endocrinology \\
DOI: $10.1530 / J O E-16-0305$ & Printed in Great Britain
\end{tabular}

of CASPASE3 increased on day 14 in RPAT, with no change in MEAT. In the same period (day 14), CASPASE9 cleavage dramatically increased in RPAT, whereas it was slightly increased on day 7 in MEAT (Fig. 1D).

Once we determined that AT atrophy may result from the decrease in the turnover of the adipocyte cell number and/or lipid reserves or both, we verified the involvement of some of the main enzymes related to lipolytic pathways, such as HSL (total and phosphorylated serine forms 563, 565 and 660). There was no change in the protein expression of HSL during the experimental period (Supplementary Fig. 1). To better understand the changes related to AT remodelling during CC, some extracellular matrix components were evaluated. Total COLLAGEN showed an increase only on day 7 with a 1.3 -fold increase $(P<0.05)$ in RPAT and 4.3-fold increase $(P<0.05)$ in MEAT (Fig. 2). Collagen and its gene expression modulators (Mmp2, Mmp9, Timp1 and Timp2) revealed no changes in RPAT at any of the time points evaluated. On the other hand, in MEAT, there was increased expression of Collagen1A1 $(69.8 \%<P<0.05)$ only on day 7 (Fig. 3A).

Published by Bioscientifica Ltd. 
Collagen $3 A 1$ gene expression did not differ at any of the experimental time points (Fig. 3B). Mmp2 gene expression increased 6.7 -fold $(P<0.01)$ only on day 7 (Fig. 3C). The Mmp9 mRNA levels were not significantly different at any of the examined times (Fig. 3D). The Timp1 mRNA levels increased 4.5 -fold $(P<0.05)$ on day 14 , whereas Timp 2 increased 62.9-fold $(P<0.01)$ on day 7 and 81.7 -fold $(P<0.05)$ on day 14 (Fig. 3E and F). However, Timp4 did not change at any of the analysed time points (Fig. 3G). Finally, expression of the $T g f B$ gene increased 5.7-fold $(P<0.05)$ only on 7 day (Fig. 3H).

\section{Discussion}

We previously demonstrated that the RPAT depot is most affected during CC syndrome and is accompanied by the marked atrophy of adipocytes (Batista et al. 2012). In this study, we also evaluated the morph-functional aspects with the aim of comparing the RPAT and MEAT profiles during CC. Thus, the cachexia model adopted here induced a decrease in the gene expression of adipogenic markers, as well as increased CASPASE 3 and CASPASE9 cleavage (apoptotic markers) in RPAT, indicating a possible impairment in cell turnover during the syndrome. Additionally, lipid turnover parameters in RPAT, as well as an ECM component profile, showed no changes during cancer. Thus, these data indicated an additional importance in cell turnover for the occurrence of RPAT atrophy.

Considering the Adiponectin to Pref1 ratio as an adipogenic parameter in AT depots, we showed a reduced adipogenic rate at the cachexia stage (day 14) from RPAT cells, indicating that adipogenesis may be reduced in this tissue. This fact confirmed previous data demonstrating that the expression of adipogenic genes are more affected in RPAT than MEAT (Batista et al. 2012), as well as an in vitro adipogenesis and co-culture study with tumour cell assays (Lopes et al. 2015). In this aspect, Bing and coworkers showed that adipogenic genes and their protein levels were decreased in epididymal AT from tumourbearing mice (Bing et al. 2006). Along these lines, our group recently showed that treatment with pioglitazone, a thiazolidinedione drug (TZD), was effective at increasing the survival of animals and was also positively correlated with the preservation of RPAT mass during cachexia, possibly through lipogenic and adipogenic positive modulation (attenuation), at least in the early stages of cachexia (Beluzi et al. 2015). Interestingly, this effect was only evident in the RPAT depot without an effect on MEAT. It is well established that TZDs are capable of enhancing the differentiation of pre-adipocytes (Kang et al. 2010, Bjorndal et al. 2011) and increasing body weight (Knights et al. 2014). Consequently, TZDs may be candidates for anti-cachectic treatment. However, further studies should address this issue to achieve a deeper understanding of possible interventions in the cachectic state.

For more information regarding AT turnover, the activation of some apoptosis pathway protein expressions, in particular, CASPASE3 and CASPASE9, were addressed in visceral depots of cachectic rats. CASPASE3 cleavage activation was only increased in RPAT, condition that seems to begin at the early stage of cachexia. CASPASE9 cleavage was also sharply increased in RPAT at the cachexia stage and slightly increased in MEAT. This condition was only evident during the cachexia stages. CASPASE9 activation by an intrinsic pathway is related to oxidative metabolic impairment (Zuo et al. 2009), a condition that is already seen in CC. Considering the information presented previously, our data corroborated the hypothesis proposed earlier by our group (Batista et al. 2012) that MEAT and RPAT respond differently during CC. RPAT is the most affected depot, with a decrease in the cell perimeter and area (Batista et al. 2012), and the increased of apoptotic marker adds new information regarding the plethora of events that results in AT atrophy. In fact, DiGirolamo and coworkers (DiGirolamo et al. 1998) showed the heterogeneity of fat depots during their expansion in normal development and RPAT expansion mainly occurs through hyperplasia than hypertrophy, unlike MEAT (DiGirolamo et al. 1998). This characteristic highlights the importance of cell proliferation for the maintenance/expansion of RPAT (DiGirolamo et al. 1998, Hausman et al. 2001).

In this way, cell turnover appears to be impaired in RPAT, possibly due to a decrease in the adipogenic process and an increase in apoptosis. Under physiological conditions, cell turnover is the balance between cell death and renewal (proliferation and differentiation) (Spalding et al. 2008). Fat mass increases in overweight and obesity are mainly due to hypertrophy, whereas in morbid obesity, hyperplasia is predominant (Arner \& Spalding 2010). Therefore, these two parameters are important to the health of adipose tissue. However, as far as we know, this is the first study that showed that AT atrophy induced by CC in RPAT might be due to reduced AT turnover in this setting.

In addition, taking into account the important role of lipid turnover to induce AT atrophy in response to CC, we verified the main lipolytic enzymes in adipocytes cells from RPAT. In these cells, no changes were demonstrated in the phosphorylated and total levels of HSL

Published by Bioscientifica Ltd 
(Supplementary Fig. 1), indicating that lipolysis seems to not be modified. However, further analyses considering additional lipid turnover parameters, such as ATGL activation, de novo lipogenesis and fat acid re-esterification, should be addressed by investigating adipocyte atrophy mechanisms in RPAT. Recently, our group showed that a drastic reduction in the Srebp1 expression occurs in RPAT in CC, whereas no change occurs in MEAT (Batista et al. 2012). Taking into account that SREBP1 is a transcription factor that acts as a positive regulator of lipogenesis processes (Shimano et al. 1999), this metabolic pathway might be downregulated in RPAT. Based on this context, we hypothesised that atrophy in RPAT occurs because of impairment in cellular AT turnover and adipocyte atrophy, which mainly occurs according to decreases in lipogenesis with or without discrete alterations in lipolysis.

Because AT turnover appears to be impaired in CC and considering that adipogenesis and apoptosis are modulated by the ECM (Mariman \& Wang 2010), we analysed some ECM components. The level of COLLAGEN deposition in the ECM is dependent on the balance of regulators. Mmp and Timp gene expression changes took place only in MEAT, and $T g f B$ changes also occurred, which among their other roles, indirectly contribute to collagen deposition (Maurer et al. 2010). This change in ECM components is evident only in MEAT, which was previously shown to be more resistant to the effects of cachexia (Batista et al. 2012). The changes in ECM components from MEAT may represent a pathway to maintain the normal physiological state, which does not occur in RPAT. However, more studies are needed to understand the possible role of ECM responses in AT during the development of CC. In this way, despite the ECM rearrangement of epididymal (mice) (Bing et al. 2006) and subcutaneous (patients) (Batista et al. 2016) AT, which has already been demonstrated to be induced by CC, our study provided new data regarding MEAT and RPAT rearrangements, showing a heterogeneity of fibrosis induced by CC. However, the consequence of such changes requires further investigation. In summary, our study demonstrated that the occurrence of the impairment of cellular turnover in RPAT occurred throughout the decrease in adipogenesis and increase in apoptotic markers, suggesting the additional importance of maintaining the cellularity of RPAT mass. Such a modification was not followed by robust impairment of lipid turnover or ECM component modification. On the other hand, in the MEAT depot, despite the lack of changes in cell turnover markers, it was shown that ECM component changes occurred, demonstrating the heterogeneous response of visceral adipose depots during
CC. Finally, the data demonstrated that the RPAT is particularly affected by CC, and a deeper understanding of AT heterogeneity responses due to cachexia may be an important topic to develop a deeper understanding of AT remodelling.

\section{Supplementary data}

This is linked to the online version of the paper at http://dx.doi.org/10.1530/ JOE-16-0305.

\section{Declaration of interest}

The authors declare that there is no conflict of interest that could be perceived as prejudicing the impartiality of the research reported.

\section{Funding}

The research described in this report was supported by FAPESP grant 2010/51078-1, 2012/00488-0 and 2015/19259-0 and CNPq 311966/2015-2.

\section{Acknowledgements}

The contents of this work are solely the responsibility of the authors and do not necessarily represent the official views of FAPESP.

\section{References}

Agustsson T, Ryden M, Hoffstedt J, van Harmelen V, Dicker A, Laurencikiene J, Isaksson B, Permert J \& Arner P 2007 Mechanism of increased lipolysis in cancer cachexia. Cancer Research 67 5531-5537. (doi:10.1158/0008-5472.CAN-06-4585)

Allison SJ 2014 Fibrosis: regulation of fibrotic signalling by TGF-beta receptor tyrosine phosphorylation. Nature Reviews Nephrology 10484. (doi:10.1038/nrneph.2014.127)

Arner P \& Langin D 2014 Lipolysis in lipid turnover, cancer cachexia, and obesity-induced insulin resistance. Trends in Endocrinology and Metabolism 25 255-262. (doi:10.1016/j. tem.2014.03.002)

Arner P \& Spalding KL 2010 Fat cell turnover in humans. Biochemical and Biophysical Research Communications 396 101-104. (doi:10.1016/j. bbrc.2010.02.165)

Batista ML Jr, Neves RX, Peres SB, Yamashita AS, Shida CS, Farmer SR \& Seelaender M 2012 Heterogeneous time-dependent response of adipose tissue during the development of cancer cachexia. Journal of Endocrinology 215 363-373. (doi:10.1530/JOE12-0307)

Batista ML Jr, Olivana M, Alcantarab PSM, Sandovala R, Peresd SB, Nevesa RX, Silverioa R, Maximianob LF, Otochb JP \& Seelaendera M 2013 Adipose tissue-derived factors as potential biomarkers in cachectic cancer patients. Cytokine 61 532-539. (doi:10.1016/j. cyto.2012.10.023)

Batista ML Jr, Henriques FS, Neves RX, Olivan MR, Matos-Neto EM, Alcantara PS, Maximiano LF, Otoch JP, Alves MJ \& Seelaender M 2016 Cachexia-associated adipose tissue morphological rearrangement in gastrointestinal cancer patients. Journal of Cachexia, Sarcopenia and Muscle 7 37-47. (doi:10.1002/jcsm.12037)

Beluzi M, Peres SB, Henriques FS, Sertie RA, Franco FO, Santos KB, Knobl P, Andreotti S, Shida CS, Neves RX, et al. 2015 Pioglitazone treatment increases survival and prevents body weight loss in tumor-bearing animals: possible anti-cachectic effect. PLOS ONE 10 e0122660. (doi:10.1371/journal.pone.0122660)

Published by Bioscientifica Ltd. 
Bertevello PS \& Seelaender MC 2001 Heterogeneous response of adipose tissue to cancer cachexia. Brazilian Journal of Medical and Biological Research 34 1161-1167. (doi:10.1590/s0100$879 \times 2001000900009)$

Bing C, Russell S, Becket E, Pope M, Tisdale MJ, Trayhurn P \& Jenkins JR 2006 Adipose atrophy in cancer cachexia: morphologic and molecular analysis of adipose tissue in tumour-bearing mice. British Journal of Cancer 95 1028-1037. (doi:10.1038/sj.bjc.6603360)

Bjorndal B, Burri L, Staalesen V, Skorve J \& Berge RK 2011 Different adipose depots: their role in the development of metabolic syndrome and mitochondrial response to hypolipidemic agents. Journal of Obesity 2011 490650. (doi:10.1155/2011/490650)

Blum D, Stene GB, Solheim TS, Fayers P, Hjermstad MJ, Baracos VE, Fearon K, Strasser F, Kaasa S \& Euro I 2014 Validation of the Consensus-Definition for Cancer Cachexia and evaluation of a classification model-a study based on data from an international multicentre project (EPCRC-CSA). Annals of Oncology 25 1635-1642. (doi:10.1093/annonc/mdu086)

Craft CS 2015 MAGP1, the extracellular matrix, and metabolism. Adipocyte 4 60-64. (doi:10.4161/adip.32209)

Das SK, Eder S, Schauer S, Diwoky C, Temmel H, Guertl B, Gorkiewicz G, Tamilarasan KP, Kumari P, Trauner M, et al. 2011 Adipose triglyceride lipase contributes to cancer-associated cachexia. Science 333 233-238. (doi:10.1126/science.1198973)

DiGirolamo M, Fine JB, Tagra K \& Rossmanith R 1998 Qualitative regional differences in adipose tissue growth and cellularity in male Wistar rats fed ad libitum. American Journal of Physiology 274 R1460-R1467.

Ebadi M \& Mazurak VC 2014 Evidence and mechanisms of fat depletion in cancer. Nutrients 6 5280-5297. (doi:10.3390/nu6115280)

Filipecki AT, Machado CJ, Valle S \& Teixeira Mde O 2011 The Brazilian legal framework on the scientific use of animals. ILAR Journal $\mathbf{5 2}$ E8-E15. (doi:10.1093/ilar.52.1.E8)

Hausman DB, DiGirolamo M, Bartness TJ, Hausman GJ \& Martin RJ 2001 The biology of white adipocyte proliferation. Obesity Reviews 2 239-254. (doi:10.1046/j.1467-789X.2001.00042.x)

Iwayama T, Steele C, Yao L, Dozmorov MG, Karamichos D, Wren JD \& Olson LE 2015 PDGFRalpha signaling drives adipose tissue fibrosis by targeting progenitor cell plasticity. Genes and Development 29 1106-1119. (doi:10.1101/gad.260554.115)

Junquiera LC, Junqueira LC \& Brentani RR 1979 A simple and sensitive method for the quantitative estimation of collagen. Analytical Biochemistry 94 96-99. (doi:10.1016/0003-2697(79)90795-4)

Kang JG, Park CY, Ihm SH, Yoo HJ, Park H, Rhee EJ, Won JC, Lee WY, Oh KW, Park SW, et al. 2010 Mechanisms of adipose tissue redistribution with rosiglitazone treatment in various adipose depots. Metabolism 59 46-53. (doi:10.1016/j.metabol.2009.07.004)

Knights AJ, Funnell AP, Pearson RC, Crossley M \& Bell-Anderson KS 2014 Adipokines and insulin action: a sensitive issue. Adipocyte 3 88-96. (doi:10.4161/adip.27552)

Lafontan M 2014 Adipose tissue and adipocyte dysregulation. Diabetes and Metabolism 40 16-28. (doi:10.1016/j.diabet.2013.08.002)

Lopes MA, Henriques FS, Franco FO, Leal LG, Vieira JC, Santos KBNH, Knobl PV, Peres SB \& Batista ML Jr 2015 Effects of LLC tumoral secretory products in coculture system on adipocyte differentiation. Abstracts of the 8th International Conference on Cachexia, Sarcopenia and Muscle Wasting, Paris, France, 4-6 December 2015. Journal of Cachexia, Sarcopenia and Muscle 6452 Abstract 3-18. (doi:10.1002/jcsm.1208)

Machado AP, Costa Rosa LF \& Seelaender MC 2004 Adipose tissue in Walker 256 tumour-induced cachexia: possible association between decreased leptin concentration and mononuclear cell infiltration. Cell and Tissue Research 318 503-514. (doi:10.1007/ s00441-004-0987-2)
Mariman EC \& Wang P 2010 Adipocyte extracellular matrix composition, dynamics and role in obesity. Cellular and Molecular Life Sciences $\mathbf{6 7}$ 1277-1292. (doi:10.1007/s00018-010-0263-4)

Martella E, Bellotti C, Dozza B, Perrone S, Donati D \& Lucarelli E 2014 Secreted adiponectin as a marker to evaluate in vitro the adipogenic differentiation of human mesenchymal stromal cells. Cytotherapy 16 1476-1485. (doi:10.1016/j.jcyt.2014.05.005)

Maurer B, Stanczyk J, Jungel A, Akhmetshina A, Trenkmann M, Brock M, Kowal-Bielecka O, Gay RE, Michel BA, Distler JH, et al. 2010 MicroRNA-29, a key regulator of collagen expression in systemic sclerosis. Arthritis and Rheumatology 62 1733-1743. (doi:10.1002/ art.27443)

Neves RXR-N JC, Yamashita AS, Matos-Neto EM, Riccardi DMR, Lira FS, Batista ML Jr \& Seelaender M 2015 White adipose tissue cells and the progression ofcachexia: inflammatory pathways. Journal of Cachexia, Sarcopenia and Muscle 7 193-203. (doi:10.1002/jcsm.12041)

O'Connell J, Lynch L, Hogan A, Cawood TJ \& O'Shea D 2011 Preadipocyte factor- 1 is associated with metabolic profile in severe obesity. Journal of Clinical Endocrinology and Metabolism 96 E680-E684. (doi:10.1210/jc.2010-2026)

Petruzzelli M, Schweiger M, Schreiber R, Campos-Olivas R, Tsoli M, Allen J, Swarbrick M, Rose-John S, Rincon M, Robertson G, et al. 2014 A switch from white to brown fat increases energy expenditure in cancer-associated cachexia. Cell Metabolism 20 433-447. (doi:10.1016/j.cmet.2014.06.011)

Rodbell M 1964 Metabolism of isolated fat cells. I. Effects of hormones on glucose metabolism and lipolysis. Journal of Biological Chemistry 239 375-380.

Ryden M, Agustsson T, Laurencikiene J, Britton T, Sjolin E, Isaksson B, Permert J \& Arner P 2008 Lipolysis-not inflammation, cell death, or lipogenesis-is involved in adipose tissue loss in cancer cachexia. Cancer 113 1695-1704. (doi:10.1002/cncr.23802)

Sanjabi S, Zenewicz LA, Kamanaka M \& Flavell RA 2009 Anti-inflammatory and pro-inflammatory roles of TGF-beta, IL-10, and IL-22 in immunity and autoimmunity. Current Opinion in Pharmacology 9 447-453. (doi:10.1016/j.coph.2009.04.008)

Seelaender MC \& Batista ML 2014 Adipose tissue inflammation and cancer cachexia: the role of steroid hormones. Hormone Molecular Biology and Clinical Investigation 17 5-12. (doi:10.1515/hmbci-2013-0040)

Shimano H, Yahagi N, Amemiya-Kudo M, Hasty AH, Osuga J, Tamura Y, Shionoiri F, Iizuka Y, Ohashi K, Harada K, et al. 1999 Sterol regulatory element-binding protein-1 as a key transcription factor for nutritional induction of lipogenic enzyme genes. Journal of Biological Chemistry 274 35832-35839. (doi:10.1074/jbc.274.50.35832)

Spalding KL, Arner E, Westermark PO, Bernard S, Buchholz BA Bergmann O, Blomqvist L, Hoffstedt J, Naslund E, Britton T, et al. 2008 Dynamics of fat cell turnover in humans. Nature 453 783-787. (doi:10.1038/nature06902)

Su BH, Tseng YL, Shieh GS, Chen YC, Wu P, Shiau AL \& Wu CL 2016 Over-expression of prothymosin-alpha antagonizes TGFbeta signalling to promote the development of emphysema. Journal of Pathology 238 412-422. (doi:10.1002/path.4664)

Sun K, Tordjman J, Clement K \& Scherer PE 2013 Fibrosis and adipose tissue dysfunction. Cell Metabolism 18 470-477. (doi:10.1016/j. cmet.2013.06.016)

Warne JP 2003 Tumour necrosis factor alpha: a key regulator of adipose tissue mass. Journal of Endocrinology 177 351-355. (doi:10.1677/ joe.0.1770351)

Zuo Y, Xiang B, Yang J, Sun X, Wang Y, Cang H \& Yi J 2009 Oxidative modification of caspase- 9 facilitates its activation via disulfidemediated interaction with Apaf-1. Cell Research 19 449-457. (doi:10.1038/cr.2009.19)

Received in final form 21 December 2016

Accepted 4 January 2017

Accepted Preprint published online 4 January 2017 http://joe.endocrinology-journals.org

DOI: $10.1530 / \mathrm{JOE}-16-0305$ (c) 2017 Society for Endocrinology Printed in Great Britain
Published by Bioscientifica Ltd. 